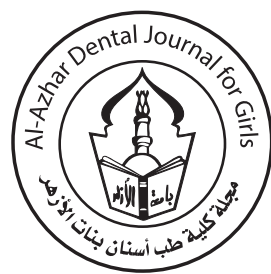

\title{
The Pattern of Dental Care Utilization Among Saudi School Children
}

\author{
Rabaa M.Aboubakr ${ }^{1 *}$, Wahdan M.A. Elkwatehy ${ }^{2}$
}

Codex : 19/21.07

azhardentj@azhar.edu.eg

http://adjg.journals.ekb.eg

DOI: $10.21608 /$ adjg.2021.60122.1337

Pediatric Dentistry \& Orthodontics ( Pediatric Dentistry, Orthodontics)

\section{KEYWORDS}

Utilization, Dental care, Saudi

Arabia, Children

\begin{abstract}
Purpose: The current study was established to evaluate the utilization and determine types of dental services provided to Saudi school children. Materials and Methods: A cross-sectional study was performed at Al Riyadh city, a sample of 5050 Saudi children of both genders with age range 6 - 9 years old was included. Dental caries was recorded according to WHO diagnostic criteria. Decayed, filled and missed teeth due to caries were recorded using $\mathrm{dmft}$ index, existing stainless-steel crowns and fissure sealants were recorded. Results: The prevalence of dental caries was $74.9 \%$ with caries experience of $3.22 \pm 3.25 \& 26.1 \%$ of the participants had pit and fissure sealant and $22.8 \%$ had stainless-steel crown. The care index was $37.4 \%$ for all children $(34.7 \%$ for male and $38.6 \%$ for female), the restorative index was $44.2 \%$ (41.4\% for male and $45.4 \%$ for female), the unmet treatment need index was $55.8 \%$ (58.6\% for male and $54.6 \%$ for female). Conclusion: caries prevalence and severity were decreased significantly compared to previous studies but still higher than the target established by the WHO. The utilization of dental care still less than average especially among governmental school children.
\end{abstract}

\section{INTRODUCTION}

Oral health problems include a wide range of chronic conditions like; dental caries, periodontal diseases, and oral cancers. Although most of oral diseases can be prevented, they still affect over 3.5 billion people worldwide ${ }^{(1)}$.

The child's first dental visit to the dentist is highly recommended and should be in the first year of his/her life or with the eruption of the first

1. Associate Professor of Dental Public Health and Preventive Dentistry, Department of Pediatric Dentistry and Dental Public Health, Faculty of Dentistry, Mansoura University, Egypt.

2. Associate Professor of Dental Public Health and Preventive Dentistry, Department of Pediatric Dentistry and Dental Public Health, Faculty of Dentistry, Mansoura University, Egypt.

* Corresponding author email: rabaa4444mahmoud@gmail.com 
primary tooth ${ }^{(2)}$. This visit is very important to build the behavior of children toward dental care practice and motivating them to continue regular checkups ${ }^{(3)}$. The children who had acceptable first dental visit usually develop regular dental visits through his/her childhood, more utilization of dental health services at adulthood. The successful dental visits provide good chances for application of preventive strategies and oral health education for the children and their parents or caregivers. Developed and developing countries have high variations and inequalities in utilization of oral health services ${ }^{(4)}$. In Europe, a high variability in dental care utilization was found among school children and all over the life of the persons ${ }^{(5)}$.

The utilization of oral health services by children before school admission was affected by the attitude of their parents or caregivers toward these services. Also, it is evidenced that parents' education level affect children's utilization of oral health services ${ }^{(6)}$. The utilization of oral health services affected by different family factors like; parents' educational level and socioeconomic status, beliefs and the perception about oral and dental health conditions of their children ${ }^{(7-9)}$. In addition to that, several factors such as demographic factors like age and gender ${ }^{(8,9)}$ as well as dental insurance ${ }^{(6)}$ and dental fear ${ }^{(10)}$ have been reported to affect the oral health service utilization.

The health service utilization can be improved by identification of different factors affecting it (predisposing factors, enabling resources and need) and application of the suitable methods which improve the health behavior and health outcomes ${ }^{(11,12)}$. Many studies were carried out in developed countries ${ }^{(13-16)}$ as well as developing countries ${ }^{(10,17-19)}$ to assess and evaluate the utilization of dental services provided among the preschool children.

Several previous studies determined the dental caries prevalence among Saudi children (20-23). According to recently performed systematic review, the prevalence and severity of dental caries were $80 \%$ prevalence and mean dmft 5.0 among primary schools' Saudi children ${ }^{(24)}$. Also, the same characteristic of caries prevalence and severity was noticed among the children of the Arab Gulf countries ${ }^{(25)}$.

There was continuous improvement in dental health care services provided to Saudi population in accordance of Saudi Arabia kingdom vision $2030^{(26)}$. Also, there is a great concern for dental treatment and dental health promotion among the school children ${ }^{(27)}$. Several studies analyzed factors associated with utilization of dental services, however, few of them recorded the rate of utilization or the types of provided dental health services in Saudi Arabia. The current study was designed to evaluate and assess the utilization rate and types of dental services provide to primary school children in Saudi Arabia.

\section{MATERIALS AND METHOD}

\section{Study design and ethical approval}

The current cross-sectional study was carried out at Al Riyadh city, Saudi Arabia during the period from August 2017 till October 2019.

The ethical approval and permission to examine school children for data collection were obtained from Ministry of Education, Kingdom of Saudi Arabia (the schools' authorities were officially informed, arrangement school visitation at specific day for data collection was done). Assigned informed consents with agreement to examine the children were obtained from their parents prior to the examination day.

\section{Sample size and sampling technique}

At Al Riyadh city, there are 1364 primary schools [969 governmental (456 for girls and 513 for boys) and 395 privates (232 for girls and 163 for boys)]. A proportional sample of 28 primary schools [10 public ( 5 for girls and 5 for boys) and 8 private ( 5 for girls and 3 for boys)] were randomly selected 
from five locations (North, East, West, South, and Central) within Al Riyadh city. A convenient sample of male and female school children with age range from 6 to 9 years old whose parents gave assigned consents with agreement was selected. A total sample of 5050 children of both genders participated in the study (2830 children from private and 2220 from public schools).

\section{Data collection}

Twelve examiners were allocated into two separate teams (male and female team) for dental examination. The intra and inter examiner calibration were assessed before study using Kapa test, the intra examiner stability was $89 \%$ and inter examiner stability was $86 \%$.

Data collection was based on clinical investigation of the proposed children. Dental caries was recorded according to World health organization (WHO) caries diagnostic criteria ${ }^{(28)}$. Decayed, filled and missed teeth due to caries as well as existing stainless-steel crowns and sealants were scored. Visual examination was done using portable light and plane mirror after wiping of their teeth with a gauze piece. The total dental caries experience (summation of decayed, missed and filled $=\mathrm{dmft}$ Index) was calculated for each child. Teeth with recurrent dental caries (filled tooth with decay) were recorded as decayed, caries diagnosis depend on clinical examination only and no radiographs were used during dental caries scoring.

The parents or caregivers were informed about the dental health status of their children's through standardized sheets prepared before the study and sent to the parents through the school channels. The parents were advised to seek dental treatment at the preventive dentistry department clinics at the dental hospital of the Al-Farabi dental college.

\section{Statistical analysis}

The collected scores were organized, tabulated, and analyzed using SPSS program (version 22, IBM,
Corp., Chicago, IL, USA). The prevalence of dental caries was calculated by gathering the children with caries experience at least score one or more divided by the total number of children. Care index was calculated according this formula (filled teeth $/ \mathrm{d}+\mathrm{m}+\mathrm{f}$ teeth) x 100, and Restorative index was calculated according to this equation (filled teeth/d+f teeth) $\mathrm{x}$ 100. While unmet treatment need index was calculated from this equation (decayed teeth $/ \mathrm{d}+\mathrm{f}$ teeth) $\mathrm{x}$ 100. Percentages of children in relation to the level of dental caries experience (dmft), decayed, missed and filled teeth were estimated using pie charts. Comparison of frequencies was estimated using chi-square test, while comparison between means was done using independent student t-test.

\section{RESULTS}

The differences between male and female children regarding the mean of all variables were statistically non-significant except for decayed teeth where the difference was significant $(\mathrm{p}=0.039)$. The differences between private and governmental school children were statistically significant for all variables $(\mathrm{p}=0.000)$ except the age $(\mathrm{p}=0.208)$ (Table 1$)$.

The range of decayed teeth was from 0 to 9 teeth with $44 \%$ of children did not have decayed teeth, $21 \%$ had $1,9 \%$ had $2,10 \%$ had 3,12\% had 4, $2 \%$ had 7 and $2 \%$ had 9 decayed teeth (Figure 1).

The range of missed teeth due to caries was from 0 to 4 teeth; there were $74 \%$ of children did not have missed teeth, $14 \%$ had 1, 5\% had 2, 2\% had 3 and $5 \%$ had 4 missed teeth due to caries (Figure 2).

The range of filled teeth was from 0 to 8 teeth; there were $49 \%$ of children did not have filled teeth, $24 \%$ had $1,14 \%$ had $2,6 \%$ had $3,2 \%$ had $6,2 \%$ had 7 and $2 \%$ had 8 filled teeth (Figure 3).

The range of $\mathrm{dmft}$ (dental caries experience) was from 0 to 13 teeth; about $25 \%$ of children were caries free, $21 \%$ had $1,7 \%$ had $2,12 \%$ had 3,14\% had $4,7 \%$ had $5,2 \%$ had $6,7 \%$ had $8,2 \%$ had 9 and $2 \%$ had 13 decayed, missed or filled tooth (Figure 4). 
Table (1) Comparison between male and female \& private and governmental school children regarding the dental caries experience.

\begin{tabular}{cccccccc}
\hline \multirow{2}{*}{ Variables } & \multicolumn{3}{c}{ Gender } & \multicolumn{3}{c}{ School type } & Total \\
\cline { 2 - 7 } & $\begin{array}{c}\text { Male } \\
\text { Mean } \pm \text { SD }\end{array}$ & $\begin{array}{c}\text { Female } \\
\text { Mean } \pm \text { SD }\end{array}$ & $\mathbf{P}$ & $\begin{array}{c}\text { Private } \\
\text { Mean } \pm \text { SD }\end{array}$ & $\begin{array}{c}\text { Public } \\
\text { Mean } \pm \text { SD }\end{array}$ & P & Mean \pm SD \\
\hline Age & $7.36 \pm 0.98$ & $7.25 \pm 1.09$ & 0.103 & $7.24 \pm 0.83$ & $7.31 \pm 1.01$ & 0.208 & $8.02 \pm 0.95$ \\
d & $1.61 \pm 1.93$ & $1.48 \pm 2.04$ & $0.039^{*}$ & $0.76 \pm 1.24$ & $2.50 \pm 2.34$ & $0.000^{*}$ & $1.52 \pm 2.00$ \\
m & $0.52 \pm 1.07$ & $0.48 \pm 1.00$ & 0.140 & $0.42 \pm 0.92$ & $0.58 \pm 1.15$ & $0.000^{*}$ & $0.49 \pm 1.03$ \\
$\mathbf{f}$ & $1.13 \pm 1.75$ & $1.24 \pm 1.88$ & 0.073 & $1.04 \pm 1.70$ & $1.41 \pm 1.99$ & $0.000^{*}$ & $1.20 \pm 1.85$ \\
$\mathbf{d m f t}$ & $3.27 \pm 3.07$ & $3.20 \pm 3.33$ & 0.451 & $2.22 \pm 1.99$ & $4.50 \pm 4.01$ & $0.000^{*}$ & $3.22 \pm 3.25$ \\
\hline
\end{tabular}

$d=$ decayed tooth, $m=$ missed tooth due to caries, $f=$ filled tooth, $S D=$ standard deviation, $p=p$ value calculated by independent student $t$ test,${ }^{*}=$ statistically significant $p$ value.

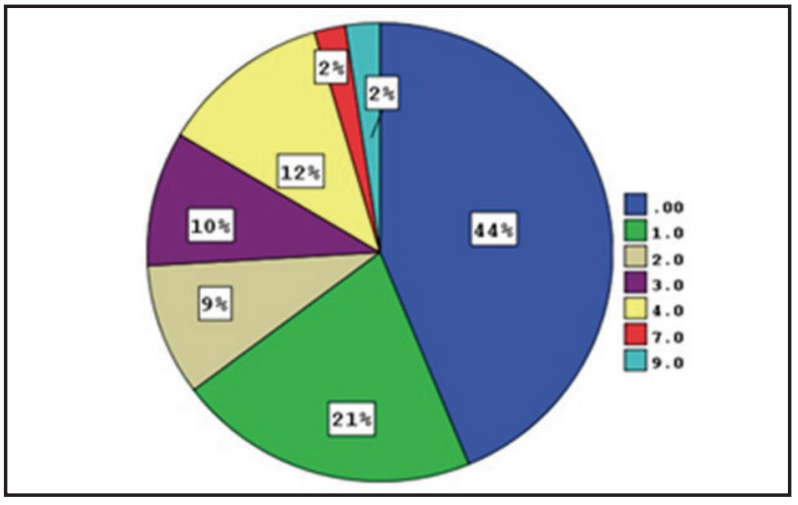

Figure 1: Percentage of children in relation to decayed teeth number

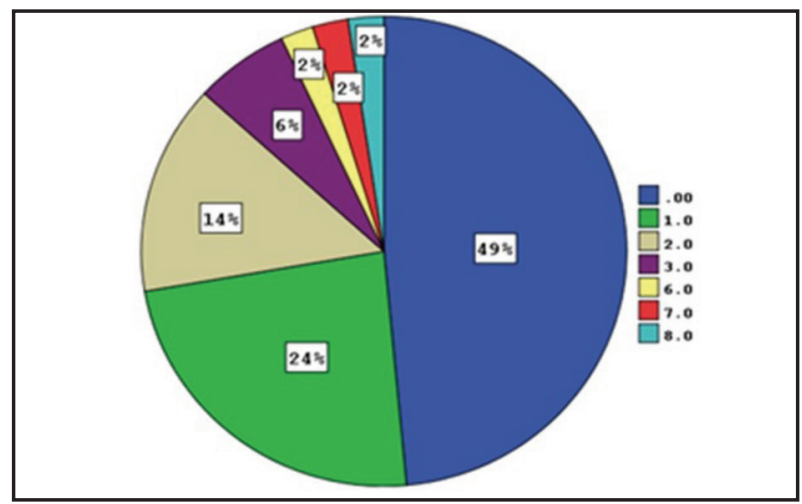

Figure 3: Percentage of children with different number of filled teeth

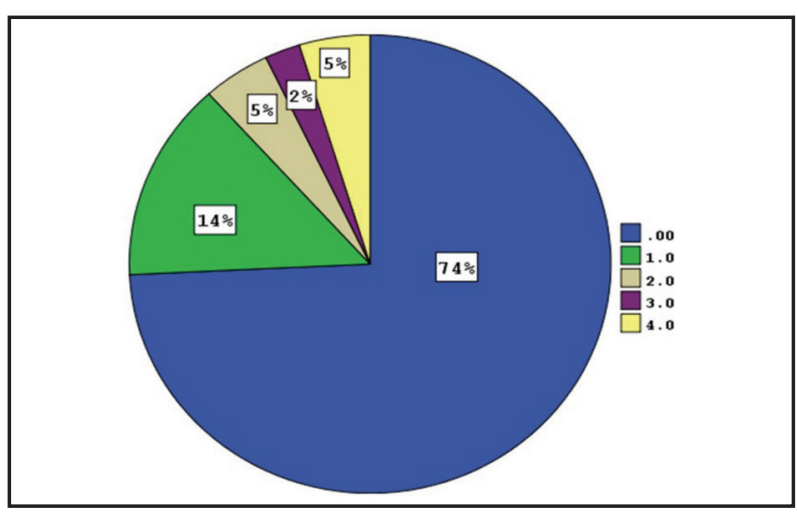

Figure 2: Percentage of children with different number of missed teeth

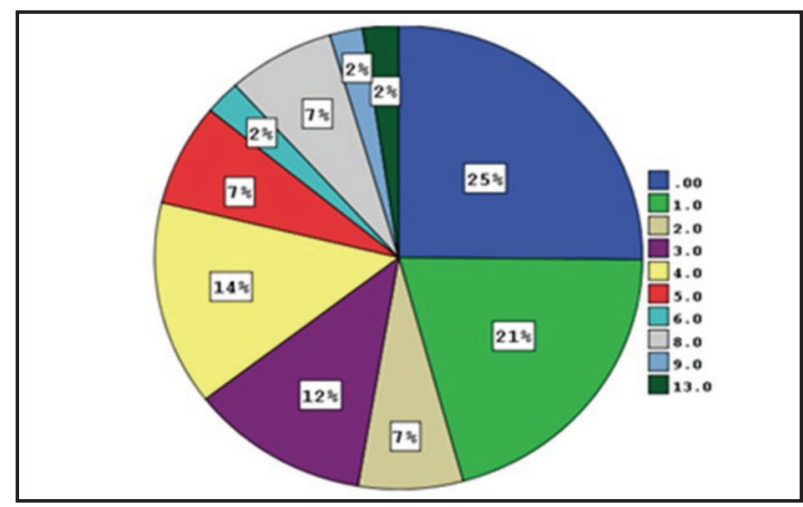

Figure 4: Percentage of children in relation to dental caries experience scores 
The differences between male and female children were statistically significant $(\mathrm{p}=0.000)$ regarding caries prevalence but not significant regarding fissure sealant and stainless-steel crown utilization $(\mathrm{p}=0.165$ and $\mathrm{p}=0.074)$. The differences between private and governmental school children regarding caries prevalence, utilization of fissure sealant and stainless-steel crown were statistically significant ( $\mathrm{p}=0.000$ for all) (Table 2$)$.
The care index was $37.4 \%$ for all children $(34.7 \%$ for male and $38.6 \%$ for female), (46.7\% for private and $31.5 \%$ for governmental) school children. The restorative index was $44.2 \%$ for all children $(41.4 \%$ for male and $45.4 \%$ for female), (57.8\% for private and $36.2 \%$ for governmental) school children. The unmet treatment need index was $55.8 \%$ for all children (58.6\% for male and $54.6 \%$ for female), (42.3\% for private and $63.8 \%$ for governmental) school children (Table 3).

Table (2) Prevalence of dental caries, sealant and stainless-steel crown utilization among Saudi school children in relation to gender and school type

\begin{tabular}{|c|c|c|c|c|c|c|c|c|}
\hline \multirow{2}{*}{\multicolumn{2}{|c|}{ Variables }} & \multicolumn{3}{|c|}{ Gender } & \multicolumn{3}{|c|}{ School type } & \multirow[b]{2}{*}{ Total } \\
\hline & & $\begin{array}{c}\text { Male } \\
\text { No. }(\%)\end{array}$ & $\begin{array}{l}\text { Female } \\
\text { No. }(\%)\end{array}$ & $\mathbf{P}$ & $\begin{array}{c}\text { Private No. } \\
(\%)\end{array}$ & $\begin{array}{c}\text { Public } \\
\text { No. }(\%)\end{array}$ & $\mathbf{P}$ & \\
\hline \multirow{2}{*}{$\begin{array}{l}\text { Dental } \\
\text { caries }\end{array}$} & Caries free & $336(21.4)$ & 934 (26.9) & \multirow{2}{*}{$0.000^{*}$} & $1040(36.7)$ & $230(10.4)$ & \multirow{2}{*}{$0.000^{*}$} & $1270(25.1)$ \\
\hline & With caries & 1238 (78.6) & $2542(73.1)$ & & $1790(63.3)$ & 1990 (89.6) & & 3780 (74.9) \\
\hline \multirow{2}{*}{$\begin{array}{l}\text { Fissure } \\
\text { sealant }\end{array}$} & Not sealed & 1148 (72.9) & $2582(74.3)$ & \multirow{2}{*}{0.165} & 1750 (61.8) & $1980(89.2)$ & \multirow{2}{*}{$0.000^{*}$} & $3730(73.9)$ \\
\hline & Sealed & $426(27.1)$ & 894 (25.7) & & $1080(38.2)$ & $240(10.8)$ & & $1320(26.1)$ \\
\hline \multirow{2}{*}{ Crown } & No crown & $1236(78.5)$ & $2664(76.6)$ & \multirow{2}{*}{0.074} & 2260 (79.9) & $1640(73.9)$ & \multirow{2}{*}{$0.000^{*}$} & $3900(77.2)$ \\
\hline & With crown & $338(21.5)$ & $812(23.4)$ & & $570(20.1)$ & $580(26.1)$ & & $1150(22.8)$ \\
\hline \multicolumn{2}{|c|}{ Total } & $1574(100)$ & $3476(100)$ & & $2830(100)$ & $2220(100)$ & & $5050(100)$ \\
\hline
\end{tabular}

No. $(\%)=$ Number of children (percentage),$p=p$ value calculated by Chi square test,${ }^{*}=$ statistically significant p value.

Table (3) The total number of decayed, missed and filled teeth and the dental care utilization among Saudi school children in relation to gender and school type

\begin{tabular}{cccccc}
\hline \multirow{2}{*}{ Variables } & \multicolumn{2}{c}{ Gender } & \multicolumn{2}{c}{ School type } & \multirow{2}{*}{ Total } \\
\cline { 2 - 5 } & Male & Female & Private & Public & 7690 \\
\hline $\mathrm{d}$ & 2533 & 5157 & 2150 & 5540 & 2490 \\
$\mathbf{m}$ & 826 & 1664 & 1200 & 1290 & 6080 \\
f & 1786 & 4294 & 2940 & 3140 & 16260 \\
Care index & 5145 & 11115 & 6290 & 9970 & $37.4 \%$ \\
\hline $\begin{array}{c}\text { Restorative index } \\
\text { Unmet treatment }\end{array}$ & $44.7 \%$ & $38.6 \%$ & $56.7 \%$ & $36.2 \%$ & $44.2 \%$ \\
\hline need index & $58.6 \%$ & $45.4 \%$ & $42.3 \%$ & $63.8 \%$ & $55.8 \%$ \\
\hline
\end{tabular}

$d=$ decayed tooth, $m=$ missed tooth due to caries, $f=$ filled tooth, Care index $=(f / d+m+f$ teeth $) x 100$, Restorative index $=(f / d+f) x 100$, Unmet treatment need index $=(d / d+f$ teeth $) \times 100$. 


\section{DISCUSSION}

The improvement in dental health status is very important due to its effect on social interaction, appearance and self-esteem. Dental health status usually reflected on the quality of life of all peoples. Although the improvement in dental health care services provided to Saudi population, the prevalence of dental caries still at high levels. One of the causes of this high level may be the insufficient utilization of provided dental services.

The dental care services utilization detected by calculating the percentage of the peoples who access the available dental health care facilities over a specified period of time, so, the improvement in dental health outcomes can be achieved through providing adequate knowledge and motivation of all individuals to use dental health services and solve the restrictions which interfere with its utilization (29). In Saudi Arabia, oral healthcare services are provided in both governmental and private sectors. The dental clinics of the governmental sector provides complete and free access to the different care levels for all citizens ${ }^{(30)}$.

In the present study participants had $74.9 \%$ dental caries prevalence with dental caries experience $3.22 \pm 3.25$ (range from 0 to 13 ), these findings were matched with previous study carried out at Al Riyadh city ${ }^{(21)}$. Generally; the prevalence of dental caries was nearly similar in male and female children (78.6\% vs $74.3 \%$ ) but in relation to school type, it was significantly higher in governmental than private school children $(89.2 \%$ vs $63.3 \%)$ (Table 1,2 and Figure 4).

The current results indicated high caries prevalence among Saudi school children, which was still higher than the target established by WHO. These results confirmed the results obtained by previous studies carried out in Saudi Arabia (31-36). Although the high prevalence of dental caries, the current results indicated improvement in dental health status of Saudi school children as different previous studies recorded higher caries prevalence as well as caries experience scores ${ }^{(37-40)}$.
Regarding fissure sealants application among our participants, slightly low percentage of them applied it (26.1\%). Utilization of fissure sealant was not different for male and females $(27.1 \%$ vs $25.7 \%)$ while it differed significantly among private and governmental school children (38.2\% vs $10.8 \%$ ) (Table 2). Although the utilization of fissure sealant is still very low, it was higher than the percentage reported by earlier study ${ }^{(38)}$. Internationally, the utilization of fissure sealant among children was $55.6 \%$ in Germany ${ }^{(41)}$ and $59 \%$ among children in Portugal ${ }^{(42)}$. In contrast, a very low fissure sealants utilization prevalence was noted in Greek adolescents ${ }^{(43)}$.

The Utilization of stainless-steel crown in the present study was $22.8 \%$ for all participating children, this was more prevalent among females than males $(23.4 \%$ vs $21.5 \%)$ \& more prevalent among governmental than private school children (26.1\% vs $20.1 \%$ ) (Table 2). Despite this percentage still being low, it gives an important indicator about improvement in utilization of dental services provided in pediatric dentistry.

The decrease in dental caries prevalence and increased utilization of fissure sealant may indicate improvement in dental health awareness and gradual improvement in utilization of dental health care services provided for Saudi population. Although these results are somewhat satisfactory, a lot of efforts should be done to reach better results.

The results of the current study indicated that; the dental services utilization is still under the average where the care index was $37.4 \%$, restorative index was $44.2 \%$ and unmet treatment need index was $55.8 \%$. Also, the care index was better in female than males (38.6\% vs $34.7 \%$ ) and in private schools than governmental schools (46.7\% vs 31.5) (Table $3)$. This under use of dental services may be due to oral health illiteracy dentist-related factors, financial and transportation barriers ${ }^{(44,45)}$

In the present study; $56 \%$ of children had at least one decayed tooth (range from 1 to 9) 
(Figure 1). Only 19\% of children (\% of children with no decayed teeth - $\%$ of caries free children) received complete treatment of decayed teeth (figure 1 and 4) \& 32\% of them (\% of children with filled teeth - $19 \%$ received complete treatment) (figure 3) have received partial treatment of decayed teeth and $26 \%$ of them had missed teeth (range from 0 to 4 ) (Figure 2). The unmet treatment index was higher in male than female $\&$ in private schools than governmental schools (Table 3). These differences may be attributed to parents' education level, parents' socioeconomic level, beliefs and perception of their children's oral health status ${ }^{(46-48)}$.

The collective evidence from the present study alarm the dental health authorities to direct a lot of efforts toward preventive program for school children and reinforce and motivate all citizens for access the available dental health care facilities and increase the benefit from the provided services through changing their behavior about the utilization of these services

\section{CONCLUSION}

The present study concluded that, prevalence and severity of dental caries among school children were decreased significantly compared to previous studies but are still higher than the established target by WHO. The utilization of dental care is still less than average especially among governmental school children.

\section{RECOMMENDATIONS}

To improve the utilization of dental services among primary school children; the authors recommend the following:

1. Periodic health education programs should be conducted to increase the parents' awareness about the available dental services for their children.

2. Periodic screening programs should be conducted in schools for early detection of oral diseases among primary school children.
3. Mobile dental unites should be used to provide dental services for children who live in remote areas.

4. Dental practitioners who manage pediatric patients should be aware of the preventive measure that could be used for that target group.

5. Free or low expense pediatric dental services should be available to enable low income children benefit from it.

\section{ACKNOWLEDGEMENT}

The authors acknowledged all the school's principals, children's parents and the team of Al Farabi Private Colleges students at Al Riyadh city who assisted in the examination and data collection for their cooperation and support.

\section{CONFLICT OF INTEREST}

The authors declared that there is no conflict of interest.

No funding was received for this study.

\section{REFERENCES}

1. Kassebaum NJ, Smith AGC, Bernabé E, Fleming TD, Reynolds AE, Vos T, et al. GBD 2015 Oral Health Collaborators. Global, Regional, and National Prevalence, Incidence, and Disability-Adjusted Life Years for Oral Conditions for 195 Countries, 1990-2015: A Systematic Analysis for the Global Burden of Diseases, Injuries, and Risk Factors. J Dent Res. 2017 Apr; 96: 380-7. doi: 10.1177/0022034517693566. PMID: 28792274; PMCID: PMC5912207.

2. American Academy on Pediatric Dentistry; American Academy of Pediatrics. Policy on early childhood caries (ECC): classifications, consequences, and preventive strategies. Pediatr Dent. 2008-2009; 30: 40-3. PMID: 19216381.

3. Hoeft KS, Barker JC, Masterson EE. Maternal beliefs and motivations for first dental visit by low-income Mexican American children in California. Pediatr Dent. 2011; 33:392-8.

4. Petersen PE. World Health Organization global policy for improvement of oral health - world health assembly 2007. Int Dent J. 2008;58: 115-21. 
5. Listl S. Inequalities in dental attendance throughout the life-course. J Dent Res 2012; 91:91-7.

6. Sohn W, Ismail A, Amaya A, and Lepkowski J. Determinants of dental care visits among low-income African-American children. J Am Dent Assoc 2007; 138:309-18.

7. Baldani MH, Mendes YB, Lawder JA, de Lara AP, Rodrigues $\mathrm{MM}$, Antunes JL. Inequalities in dental services utilization among Brazilian low-income children: the role of individual determinants. J Public Health Dent. 2011; 71:46-53.

8. Medina-Solis CE, Maupomé G, del Socorro HM, PérezNúñez R, Avila-Burgos L, Lamadrid-Figueroa H. Dental health services utilization and associated factors in children 6 to 12 years old in a low-income country. J Public Health Dent 2008; 68:39-45.

9. Finlayson TL, Gansky SA, Shain SG, Weintraub JA. Dental utilization by children in Hispanic agricultural worker families in California. J Dent Oral Craniofac Epidemiol 2014; 2:15-24.

10. Naidu, R., Nunn, J., Forde, M. Oral healthcare of preschool children in Trinidad: a qualitative study of parents and caregivers. BMC Oral Health 12, 27 (2012). https:// doi.org/10.1186/1472-6831-12-27

11. Anderson RM. Revisiting the behavioral model and access to medical care: does it matter? J Health Soc Behav 1995; 36:1-10.

12. Isong U, Weintraub JA. Determinants of dental service utilization among 2 to 11 -year-old California children. J Public Health Dent. 2005; 65:138-45.

13. Slack-Smith LM. Dental visits by Australian preschool children. J Paediatr Child Health 2003; 39:442-5.

14. Mantonanaki M, Koletsi-Kounari H, Mamai-Homata E, Papaioannou W. Prevalence of dental caries in 5-year-old Greek children and the use of dental services: evaluation of socioeconomic, behavioural factors and living conditions. Int Dent J 2013; 63:72-9.

15. Kim J, Kaste LM. Associations of the type of childcare with reported preventive medical and dental care utilization for 1- to 5-year-old children in the United States. Community Dent Oral Epidemiol. 2013; 41:432-40.

16. Leroy R, Bogaerts K, Hoppenbrouwers K, Martens LC, Declerck D. Dental attendance in preschool children - a prospective study. Int J Paediatr Dent 2013; 23:84-93.

17. Xu, M., Yuan, C., Sun, X. et al. Oral health service utilization patterns among preschool children in Beijing, China. BMC Oral Health 18, 31 (2018). https://doi.org/10.1186/ s12903-018-0494-6
18. Granville-Garcia AF, Clementino MA, Gomes MC, Costa EM, Pinto-Sarmento TC, Paiva SM. Influence of oral problems and biopsychosocial factors on the utilization of dental services by preschool children. J Dent Child 2015; 82:76-83.

19. Medina-Solís CE, Maupomé G, Avila-Burgos L, HijarMedina M, Segovia-Villanueva A, Pérez-Núñez R. Factors influencing the use of dental health services by preschool children in Mexico. Pediatr Dent 2006; 28:285-92.

20. Mansour M, Anwar S, Pine C. Comparison of caries in 6-7 year old Saudi girls attending public and armed forces schools in Riyadh, Saudi Arabia. Saudi Dent J 2000; 12:33-6.

21. Al-Banyan RA, Echeverri EA, Narendran S, Keene HJ. Oral health survey of 5-12-year-old children of National Guard employees in Riyadh, Saudi Arabia. Int J Paediatr Dent 2000; 10:39-45.

22. Owusu GB, Al-Amri MY, Stewart BL, Sabbah W. Status of dental caries among 4-9 year-old children attending dental clinic in a military hospital in Tabuk, KSA. Saudi Dent J 2005; 17:126-31.

23. Al-Tamimi S, Petersen PE. Oral health situation of schoolchildren, mothers and schoolteachers in Saudi Arabia. Int Dent J 1998; 48:180-6.

24. Al-Agili D. A systematic review of population-based dental caries studies among children in Saudi Arabia. Saudi Dent J 2013; 25:3-11.

25. Al-Thani MH, Al-Thani AA, Al-Emadi AA, Al-Chetachi WF, Akram H, Poovelil BV. Oral health status of six-yearold children in Qatar: findings from the national oral health survey. Int J Dent Hyg 2018; 16:225-32.

26. Saudi Arabia Ministry of Health. Vision Realization Office. Healthcare Transformation Strategy [Internet]. Vision Realization Office; 2021. Available from: https:// www.moh.gov.sa/en/Ministry/vro/Documents/HealthcareTransformation .... Accessed 19 February 2021.

27. Saudi Arabia Ministry of Health. MOH: Healthy Schools Program Launched to Improve Student Health [Internet]; 2021. Available from: https://www.moh.gov.sa/en/ Ministry/MediaCenter/Ads/Pages/Ads-2019-02-28-.... Accessed 19 February 2021.

28. World Health Organization. Oral health surveys-basic methods. 5. Geneva: World Health Organization; 2013.

29. Gambhir RS, Brar P, Singh G, Sofat A, Kakar H. Utilization of dental care: An Indian outlook. Journal of Natural Science, Biology, and Medicine 2013;4:292-7. 
30. Alshahrani, A. M., Raheel, S. A. Healthcare System and Accessibility of Dental Services in Kingdom of Saudi Arabia: An Update. J Inter Oral Health 2016; 8:883-7.

31. Al-Shammery AR, Guile EE, Ei-Backly M. Prevalence of caries in primary school children in Saudi Arabia. Community Dent Oral Epidemiol. 1990; 18:320-1.

32. Alamoudi N, Salako NO, Massoud I. Caries experience of children aged 6-9 years in Jeddah, Saudi Arabia. Int J Paediatr Dent 1996; 6:101-5.

33. Paul T, Maktabi A. Caries experience of 5-year-old children in Alkharj, Saudi Arabia. Int J Paediatr Dent 1997; 7:43-4.

34. Wyne AH, Al-Ghorabi BM, Al-Asiri YA, Khan NB. Caries prevalence in Saudi primary school children of Riyadh and their teachers' oral health knowledge, attitude and practices. Saudi Med J 2002; 23:77-81.

35. Al-Malik MI, Rehbini YA. Prevalence of dental caries, severity, and pattern in age 6 to 7-year-old children in a selected community in Saudi Arabia. J Contemp Dent Pract 2006; 7:46-54.

36. Farooqi FA, Khabeer A, Moheet IA, Khan SQ, Farooq I, ArRejaie AS. Prevalence of dental caries in primary and permanent teeth and its relation with tooth brushing habits among schoolchildren in Eastern Saudi Arabia. Saudi Med J 2015; 36:737-42.

37. Al-Wazzan KA. Dental caries prevalence in 6-7year-old school children in Riyadh Region: A comparative study with the 1987 Oral Health Survey of Saudi Arabia Phase I. Saudi Dent J 2004; 16:54-60.

38. Al Dosari AM, Wyne AH, Akpata ES, Khan NB. Caries prevalence and its relation to water fluoride levels among schoolchildren in Central Province of Saudi Arabia. Int Dent J. 2004; 54:424-8.

39. Brown, A. Caries prevalence and treatment needs of healthy and medically compromised children at a tertiary care institution in Saudi Arabia. Eastern Mediterranean health J 2009; 15:378-86.
40. Alamri AA, Aldossary MS, Alshiha SA, Alwayli HM, Alfraih YK, Hattan MA. Dental caries prevalence among primary male schoolchildren in Riyadh, Saudi Arabia: A cross-sectional survey. J Int Oral Health 2017; 9: 146-50

41. Kuhnisch J, Berger S, Goddon I, Senkel H, Pitts N, Heinrich-Weltzien R. Occlusal caries detection in permanent molars according to WHO basic methods, ICDAS II and laser fluorescence measurements. Community Dent Oral Epidemiol 2008; 36:475-84.

42. Veiga NJ, Pereira CM, Ferreira PC, Correia IJ. Prevalence of dental caries and fissure sealants in a Portuguese sample of adolescents. PLoS One. 2015;10:e0121299. Published 2015 Mar 24. doi:10.1371/journal.pone.0121299

43. Oulis CJ,Berdouses ED, Mamai-Homata E, Polychronopoulou A. Prevalence of sealants in relation to dental caries on the permanent molars of 12 and 15-year-old Greek adolescents. A national pathfinder survey. BMC Public Health. 2011; 11:100-6. 44 .

44. Reda SM, Krois J, Reda SF et al. The impact of demographic, health-related and social factors on dental services utilization: systematic review and meta-analysis. J Dent 2018; 75: 1-6.

45. Quadri FA, Jafari FA, Albeshri AT et al. Factors influencing patients' utilization of dental health services in Jazan, Kingdom of Saudi Arabia. Int J Clin Pediatr Dent 2018; 11: 29-33.

46. AlHumaid J,El Tantawi M,AlAgl A et al. Dental visit patterns and oral health outcomes in Saudi children. Saudi J Med Med Sci 2018; 6: 89-94.

47. Reda SF, Reda SM, Thomson WM, Schwendicke F. Inequality in Utilization of Dental Services: A Systematic Review and Meta-analysis. Am J Public Health. 2018 Feb;108: e1-e7. doi: 10.2105/AJPH.2017.304180. Epub 2017 Dec 21. PMID: 29267052; PMCID: PMC5846590.

48. Al Agili DE., Farsi NJ. Need for dental care drives utilisation of dental services among children in Saudi Arabia. Int Dent J 2020; 70(3):183-92. 